\title{
Compressor Station Control Simulation on Variable Operating Modes
}

\author{
Dariia Budko *, German Bondarenko \\ Sumy State University, Faculty of Technical Systems and Energy Efficient Technologies, Technical Thermophysics Department, 2 Rymskogo-Korsakova \\ St., Sumy, 40007, Ukraine
}

\begin{abstract}
The algorithm, mathematical model, and computer program of compressor station (CS) operation on variable modes are developed. The operation of the compressor station is controlled by turning on or off the compressors, according to the accepted criteria of rationality. The problem of the compressor station operation with any standard sizes of compressors according to the known schedule of loading is solved. Based on the created mathematical model of the compressor station functioning the numerical research and optimization of its work is carried out.
\end{abstract}

Keywords: compressor station, air supply system, variable operating modes, mathematical model, criteria of rationality, control scenarios.

\section{Introduction}

Many publications are devoted to the problem of efficient use of energy resources in various fields [1-7]. However, the issues of comprehensive research, optimization, and energy efficiency increase in the compressed air supply system of an industrial enterprise, which takes into account the specifics of the functioning of the system as a whole, as well as its structural elements, remain insufficiently considered. The operation of the air supply system is most similar to industrial power supply systems [7-11]. By analogy with [10], where the power supply system is divided into separate blocks, the mathematical model of the air supply system is divided into submodels [12], which are interconnected by the parameters of «input-output». In present manuscript special attention is paid to optimization of the compressor station operation where inlet parameters to a pipelines network are considered set. At the same time, the capacity of the air supply system has several serious shortcomings. First of all, this is a high cost compared to electrical power, due to the high electricity power compressors consumption that generates compressed air. Compressed air flows from the compressor station to the consumer through long and branched pipelines. This flow is subject to large energy losses due to hydraulic resistance, pressure fluctuations, and temperature differences in the main pipelines [13]. Modernization issues are usually considered separately from the energy efficiency issues. Nevertheless, from a technical point of view, it's should be considered as interconnected subsystems of a unified energy supply system, designed to create conditions for efficient operation of industrial enterprises [7].

The air supply system of an industrial enterprise is dynamic. The main task of optimizing such systems is predicting and modeling its operation in real-time. This allows an increase in the basic indicators of the air supply system energy efficiency $[14,15]$.

The principles of algorithms construction control of dynamic systems and control of 
their indicators are general [16-20]. In the manuscript [21] the approach of multi-scenario management is used, which allows to optimize the operation of the compressor station by several criteria. Nevertheless, the work of compressed air supply systems of industrial enterprises has a number of features that must be taken into account when forecasting and optimizing.

Research objectives will be solved by the following methods: analysis of scientific and technical information and mathematical modeling. The analysis and scientific generalization of the information allowed substantiate actuality of a scientific problem and formulate research objectives. Mathematical modeling, as a part of the research, involved the research of the air supply system operation mode of an industrial enterprise and its optimization in accordance with the criteria of efficiency of the system by influencing the compressor station. The reliability of the obtained results is ensured by preliminary testing of the mathematical model of a simple compressor station of the air supply system, the optimality of the operation mode which easy to check.

The manuscript consists of: Experimental Section, which discussed the development of the model algorithm, given basic assumptions, identified four main scenarios for compressor station operation control, descripted the algorithm including a block diagram of the compressor station system model with dissimilar compressors, as well Results of the research and Conclusions.

\section{Experimental Section}

\subsection{Development of the model algorithm}

When constructing a compressor station control algorithm, it is first necessary to analyze the available compressors. Based on their real condition, the following features should be identified:

1. compressors types ( $R C$ - reciprocating compressor, CC - centrifugal compressor, SC - screw compressor, etc.);

2. compressors characteristics (capacity $V_{i^{\prime}}$ power consumption $N_{i^{\prime}}$ compressor outlet pressure $p_{c}$ );

3. compressors total operating time $T_{i}$;

4. compressors condition:

- "active»;

- "stand by»;

- «reserve»;

- «under repair».

Based on the analysis of compressors, their list is compiled (Fig. 1).

\begin{tabular}{|l|l|c|c|c|}
\hline $\mathrm{n}$ & Technical condition & $\mathrm{Vi}^{3} \mathrm{~m}^{3} \mathrm{~min}$ & $\mathrm{~N}, \mathrm{~kW}$ & $\mathrm{~T}, \mathrm{~h}$ \\
\hline S1-20 & Active & 20 & 127 & 1004 \\
\hline S2-10 & Active & 10 & 62,2 & 5004 \\
\hline S3-10 & Stand by & 10 & 62,2 & 6500 \\
\hline S4-20 & Active & 20 & 127 & 2004 \\
\hline S5-20 & Active & 20 & 127 & 4004 \\
\hline S6-20 & Active & 20 & 127 & 7004 \\
\hline S7-10 & Reserve & 10 & 62,2 & 2500 \\
\hline & L & 694,6 & 28020 \\
\hline
\end{tabular}

Figure 1: Example of a compressor station data file with dissimilar screw compressors.

This list serves as an information base that should be updated by the operator if the status of the compressors changes, for example:

- on/off of the compressors;

- removal from the state of «active» to a state of «under repair»;

- removal from the state of «under repair» to a state of "stand by»;

- replacement of a «reserve» compressors;

- replacement of compressors during reconstruction etc.

First of all, each compressor is assigned an identification number, which serves as a password to turn on / off the compressor according to the algorithm. For example: screw compressors: S110, S2-10; reciprocating compressor: R1-16, R2-16; centrifugal compressor: C1-250, C2-250.

The list should be updated at each control step caused by a change in consumption mode, primarily air consumption. The influence on the control system of the compressor station is carried out by the command of the external sensor, usually, it is the pressure sensor in the output receiver or the collector of the compressor station.

When air consumption changes, the pressure in the network changes: an increase in consumption causes a decrease in pressure, and a decrease in consumption, on the contrary, increases the pressure. The pressure sensor converts the pulse into an analog or digital signal, which initiates the operation of the control system of the compressor station according to the algorithm. It is important to note that the sensor is pre-set to operate when increasing or decreasing the pressure (signal «+») and decreasing pressure (signal «-») in accordance with the accepted values of maximum $p_{\max }$ and minimum $p_{\min }$ pressure.

After selecting a certain option, the system gives a control signal to turn on (or off) the corresponding compressors and updates the list of compressors status. The system is stabilized until the next signal from the pressure sensor. 
In solving this problem, the following basic assumptions were made:

1. It is believed that the pneumatic system is damped in such a way that random pressure ripples in the system are "quenched" and the pressure sensor does not respond to them.

2. It is believed that the processing of the sensor signal uses integralproportional or other systems of automatic signal processing, taking into account the derived schedule of its change, predicting the possible duration of the changed load mode. Modern systems with microprocessors allow us to do this.

3. System run time, consisting of signal processing time and compressor start (or stop) time, does not affect system performance.

There are several ways the system responds to changing system conditions, each of which pursues its own goal. Thus, we are talking about multiscenario and multi-criteria algorithms for system management. Consider the most commonly used of them.

1st scenario. Random selection of switched on and off compressor or several compressors. The criteria here is the maximum approximation of the performance of the changed compressor station $\left(V_{C S}\right)$ to the load $\left(V_{L}\right)$ (consumption):

$$
\left(V_{C S}-V_{L}\right) \rightarrow \min
$$

2nd scenario. If necessary, the compressor that works longer than others is turned off, and if it is necessary to turn on, the compressor that is in the «stand by» state for the longest time is turned on.

3rd scenario. Alignment of total operating time. Compressors are switched on or off in order to distribute the total operating time more evenly among all compressors of the compressor station. That is if you need to turn on the compressor of the required capacity $V_{C S}$, choose a compressor with a minimum operating time $T$, and if you need to turn it off - on the contrary, with a maximum $T$ :

$$
\begin{aligned}
& \text { if turnon } T=\min \\
& \text { if turn off } T=\max
\end{aligned}
$$

4th scenario. Minimization of power consumption. In this case, the decision to turn offor on a compressor is made taking into account its technical condition, specific power consumption, or efficiency.

In the task of finding the best options of the working compressors of the CS in the initial mode is set: $V_{i}$-capacity of the $i$-th compressor, $N_{i}$ - power consumption of the i-th compressor when operating at nominal mode, $V_{L}$ - load on the compressor station. It is necessary to calculate the combination of the number of operating compressors of each type, at which the total power consumed by the compressors will be minimal.

Most of the tasks of optimizing of the compressor station operation can be formulated as the task of optimizing some objective function in conditions of limited resources and the presence of competing constraints. If we can set a goal as a linear function of several variables and formulate constraints in the form of equations and inequalities that relate these variables, we obtain the problem of linear programming [16]. To write this problem as a linear programming problem, we need to define a set of variables and constraints that will determine the best combination. Thus, we obtain the following task linear programming:

Minimize $\bar{N}=\frac{N_{1} \cdot n_{1}+N_{2} \cdot n_{2}+\ldots+N_{i} \cdot n_{i}}{V_{L}} \rightarrow \min$

under conditions $\left\{\begin{array}{l}V_{1} \cdot n_{1}+V_{2} \cdot n_{2}+\ldots+V_{i} \cdot n_{i} \geq V_{L} \\ n_{1} \leq m_{1} \\ n_{2} \leq m_{2} \\ n_{i} \leq m_{i} \\ n_{1} \geq 0, n_{2} \geq 0, \ldots, n_{i} \geq 0 .\end{array}\right.$

In this task: $n_{1}, n_{2}, \ldots n_{i}$ - variables; the number of operating compressors of a certain type; $m_{1}, m_{2}, \ldots m_{i}$ - the number of certain type compressors installed at the compressor station and ready for operation. A prerequisite is to limit the integrity of the variables.

As a result, obtain a set of elements that satisfy the given conditions, namely: the minimum difference between the load on the compressor station and the performance of this compressor station, as well as the minimum power consumption by compressors.

It is also possible to implement combined management methods. In this case, an unambiguously optimal compressor station control scenario cannot be proposed. The choice of one or another method depends on the type of compressors, characteristics, and technical condition of compressors, etc.

\subsection{Description of the algorithm}

From the point of view of mathematics, the problem does not have a global optimum but has so-called situational optimums. The schematic diagram of the compressor station control is shown in Fig. 2. 


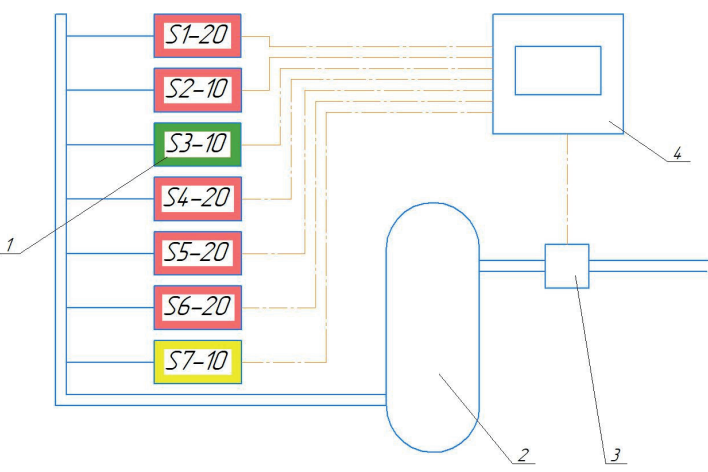

Figure 2: Schematic diagram of the compressor station control system: (1) Compressors. (2) Receiver. (3) Pressure sensor. (4) Processor.

Activation of the model algorithm initiates a signal from the sensor 3 to the drive system of the compressors 1. The signal means that the load on the compressor station (compressed air consumption) has reached the maximum or minimum value and the system must respond to this.

It should be noted that in the event of situations in which even with the intervention of the control algorithm (for example, rupture of air ducts, or a sudden consumption decrease), the system does not stabilize, should work as standard precautions.

Consider the control of a compressor station with two groups of compressors with a capacity of $20 \mathrm{~m}^{3} / \mathrm{min}$ and $10 \mathrm{~m}^{3} / \mathrm{min}$. Figure 3 shows a block diagram of the model of such control. It determines the sequence of solving subtasks, the order of decision-making to move to the next step or return to the previous step to adjust the previously made decision. The optimization of the compressor station operating is performed according to a combination of efficiency criteria of the 3rd and 4th scenarios.

The first step of the algorithm is to compare the values of the load on the compressor station $V_{L}$ and the performance of the compressor station at the initial time $V_{C S 1}$. If $V_{C S 1}>V_{L}$, there is an excess capacity of the compressor station and it is necessary to check the possibility of disconnection of one or more compressors.

In the second step, taking into account the criterion «maximum operating time $T$ », a set of elements in the state «active» is selected, in which at this time the maximum value of $T$. If this is not enough, turn off another one compressor according to the same criteria. At each step, it is necessary to wait for the reaction of the system. If the system has stabilized, the operation is considered successful.

If it turns out that $V_{C S 1}>V_{L}$ it is necessary to additionally turn on the compressor from the number in the «stand by» state, which has a minimum operating time $T$.

After performing these procedures, the system is in working condition, after which the input data (of the status of the compressor) is updated taking into account the data from the operator (about change the technical condition of the compressors) and the next control cycle of the compressor station is performed.

Thus, in the event of an external impact on the system (sensor signal), the algorithm must provide a search for the object (or objects) from the number of «active» (when reducing the load) or from the number in the «stand by» mode (when increasing load), which would best meet the conditions of optimization, but also take into account the limitations imposed by a particular management scenario. In the general case, the mathematical problem of this stage is reduced to the problem of combinatorics: from a finite set of inhomogeneous elements choose a limited set of elements that satisfies the given conditions.

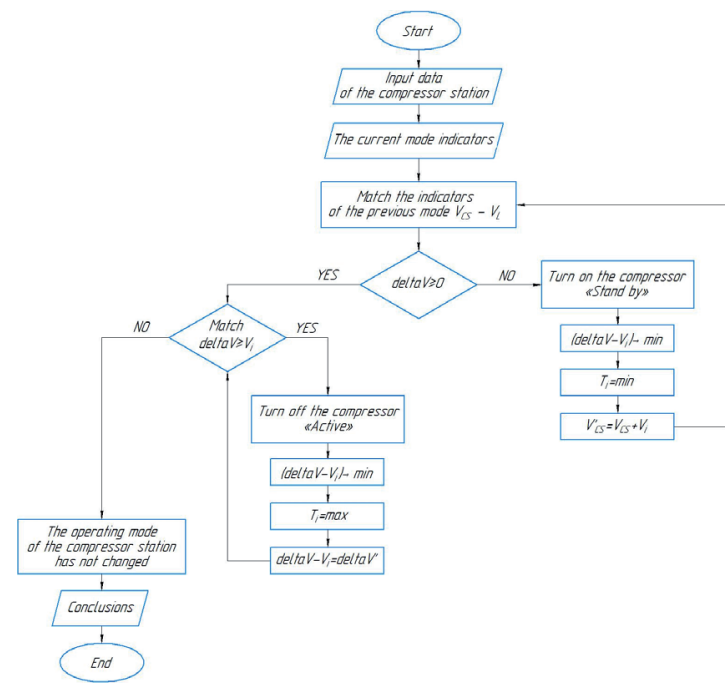

Figure 3: Block diagram of the compressor station system model with dissimilar compressors.

\section{Results and Discussion}

The air supply systems of industrial enterprises, as a rule, are individual, which is determined by the profile of activity, location of the enterprise, type, and characteristics of pneumatic equipment, mode 


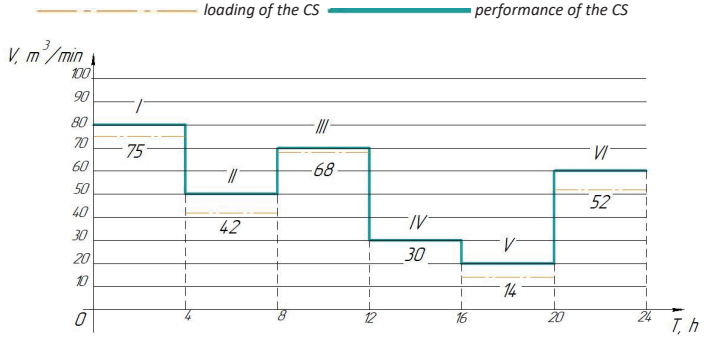

Figure 4: Daily linearized schedule of loading and performance of the compressor station.

of its operation (constant, periodic, random), type of regulation and automation, etc. The principles of construction of mathematical control models are generally universal [15-17], but the research and optimization of the system operation are performed only for a specific network, which is considered to be given, and therefore a given daily load schedule for the compressor station (Fig. 4).

As an example, consider the compressor control system of an inhomogeneous compressor station. The equipment of the compressor station includes four compressors with a capacity of $20 \mathrm{~m}^{3} / \mathrm{min}$ each and three compressors of $10 \mathrm{~m}^{3} / \mathrm{min}$ each (Fig. 2).

The first stage will be to solve the problem of selecting the best combination of working compressors with their minimum power consumption. The input data file for calculation, as well as its results, are shown in Fig. 5.

Perform the calculation for the second mode from the six modes of operation of the compressor station, shown in Fig. 4. The initial state will be the mode of the compressor station operation in the first mode: the productivity of the station $V_{C S}=80 \mathrm{~m}^{3} / \mathrm{min}$, the table of the state of the compressors is shown in Fig. 6.

As changes occur, the operator must update or adjust the data file of compressors technical condition, taking into account the need to bring compressors for scheduled maintenance or repair, or vice versa commissioning to the «stand by» state compressors after a repair, replacement of backup units, emergency shutdowns, etc. The input of such data is performed from the remote control, and processing is automatic according to the algorithm.

\section{Conclusions}

The article attempts to create a control model for dissimilar compressors of a compressor station of an industrial enterprise with variable operating modes. Multi-scenario and multi-criteria algorithms of the control model of inhomogeneous compressor station (with different compressor types) are described. Developed a computer program model, which is implemented in Microsoft Office Excel for a compressor station with two types of compressors. Some remarks on the algorithm:

\begin{tabular}{|c|c|c|c|c|c|c|c|c|c|c|c|}
\hline Input data & & & & & & Calculation re & esults & & & & \\
\hline compr type & Vi & $\mathrm{Ni}$ & $\mathrm{m}$ & №of mode & $v_{L}$ & n1(BB 20/8) & n2(нBэ 10/0,7) & $v_{c s}$ & $\Delta v$ & & \\
\hline BB 20/8 & 20 & 127 & 4 & 1 & 75 & 3 & 2 & 80 & & 5 & 505,4 \\
\hline \multirow[t]{5}{*}{ НВэ $10 / 0,7$} & 10 & 62,2 & 3 & 2 & 42 & 1 & 3 & 50 & & 8 & 313,6 \\
\hline & & & & 3 & 68 & 2 & 3 & 70 & & 2 & 440,6 \\
\hline & & & & 4 & 30 & 0 & 3 & 30 & & 0 & 186,6 \\
\hline & & & & 5 & 14 & 0 & 2 & 20 & & 6 & 124,4 \\
\hline & & & & 6 & 52 & 2 & 2 & 60 & & 8 & 378,4 \\
\hline
\end{tabular}

Figure 5: The results of the calculation of the best combination of running compressors.

\begin{tabular}{|c|c|c|c|c|c|c|}
\hline $\mathrm{v}_{\mathrm{cs}}$ & 80 & \multicolumn{2}{|c|}{ Initial state } & & & \\
\hline $\mathrm{V}_{\mathrm{L} 1}$ & 42 & $n$ & Technical condition & $\mathrm{Vi}, \mathrm{m}^{3} / \mathrm{min}$ & $\mathrm{N}, \mathrm{kW}$ & $\mathrm{T}, \mathrm{h}$ \\
\hline$\Delta \mathrm{V}$ & 38 & $S 1-20$ & Active & 20 & 127 & 1004 \\
\hline \multicolumn{2}{|c|}{ If $\Delta V \geq 0$ (Yes), compare $\Delta V \geq V i$} & $S 2-10$ & Active & 10 & 62,2 & 5004 \\
\hline \multicolumn{2}{|c|}{ If $\Delta V \geq V i$ compressors 6 (Yes) } & S3-10 & Stand by & 10 & 62,2 & 6500 \\
\hline \multicolumn{2}{|c|}{ Turn off compressor $56-20$} & $54-20$ & Active & 20 & 127 & 2004 \\
\hline$v_{c s}$ & 60 & $55-20$ & Active & 20 & 127 & 4004 \\
\hline$\Delta \mathrm{V}$ & 18 & $56-20$ & Active & 20 & 127 & 7004 \\
\hline \multicolumn{2}{|c|}{ If $\Delta V \geq V i$ compressors 2 (Yes) } & S7-10 & Reserve & 10 & 62,2 & 2500 \\
\hline \multicolumn{2}{|c|}{ Turn off compressor \$2-10 } & & $\Sigma$ & 110 & 694,6 & 28020 \\
\hline$v_{c s}$ & 50 & & & & & \\
\hline$\Delta v$ & 8 & \multicolumn{2}{|c|}{ Final state } & & & \\
\hline \multicolumn{2}{|c|}{ CS mode is persistent } & $\mathrm{n}$ & Technical condition & $\mathrm{Vi}, \mathrm{m}^{3} / \mathrm{min}$ & $\mathrm{N}, \mathrm{kW}$ & $\mathrm{T}, \mathrm{h}$ \\
\hline & & $S 1-20$ & Active & 20 & 127 & 1008 \\
\hline & & $S 2-10$ & Stand by & 10 & 62,2 & 5004 \\
\hline & & s3-10 & Stand by & 10 & 62,2 & 6500 \\
\hline & & $54-20$ & Active & 20 & 127 & 2008 \\
\hline & & $55-20$ & Active & 20 & 127 & 4008 \\
\hline & & $56-20$ & Stand by & 20 & 127 & 7004 \\
\hline & & $57-10$ & Reserve & 10 & 62,2 & 2500 \\
\hline & & & $\Sigma$ & 110 & 694,6 & 28032 \\
\hline
\end{tabular}

Figure 6: The results of the calculation of the second mode of operation of the inhomogeneous compressor station. 
1. Compressor status spreadsheets are adjusted by the operator as changes occur.

2. The updates of operating time values $T$ are performed automatically by means of counters.

3. In principle, it is possible to transmit signals to the light board from the compressor station remote control.

On a simplified example of an air compressor station with a pre-known load schedule performed a numerical implementation of a mathematical model. The calculation results are obtained in the form of spreadsheets with the most rational combinations of compressors for each mode of operation of the compressor station. The optimization of the compressor station operation was carried out according to the criteria of the minimum power consumed by the compressors, as well as the equalization of the compressor operating time.

\section{References and Notes}

1. Pustovyi, O. Yu. (2018). Organizational and Economic Mechanism of Energy Efficiency Measures at MachineBuilding Enterprises. Energy Saving. Power Engineering. Energy Audit, № 1(144), pp. 11-21 [in Russian].

2. Eichhammer, W., Mannsbart, W. (1997). Industrial Energy Efficiency - Indicators for a European Cross-Country Comparison of Energy Efficiency in the Manufacturing Industry. Energy Policy, Vol. 5, iss. 7-9, pp. 759-772.

3. Maliarenko, O. Ye. (2018). Methodical Approach to Determining the Forecast Structure of Energy Consumption Based on an Integrated Approach. The Problems of General Energy № 1(52), pp. 24-31 [in Ukrainian].

4. Price, L., Ke J., Ohshita, S. and other (2012). China's Industrial Energy Consumption Trends and Impacts of the Top1000 Enterprises Energy-Saving Program and the Ten Key Energy-Saving Projects. Energy Policy. Vol. 50, pp. 562-569.

5. Mohammadi, M., Esmaelian, M., Atighehchian, A. (2020). Design of Mathematical Models for the Integration of Purchase and Production Lot-Sizing and Scheduling Problems under Demand Uncertainty. Applied Mathematical Modelling, Vol. 84, pp. 1-18.

6. Russell, A., Taghipour, Sh. (2020). Multi-Parallel Work Centers Scheduling Optimization with Shared or Dedicated Resources in Low-Volume Low-Variety Production Systems. Applied Mathematical Modelling, Vol. 80, pp. 472-505.

7. Todorov, G.N., Volkova, E.E., Vlasov, A.I., Nikitina, N.I. (2019). Modeling Energy-Efficient Consumption at Industrial Enterprises. International Journal of Energy Economics and Policy, Vol. 9, No. 2, pp. 10-18.

8. Yanrong Lu, Fucheng Liao, Jiamei Deng, Huiyang Liu. (2017)
Cooperative Global Optimal Preview Tracking Control of Linearmulti-Agent Systems: An Internal Model Approach. International Journal of Systems Science. Vol. 48, No. 12, pp. 2451-2462.

9. Trip, S., Cucuzzella, M., Claudio De Persis, Ferrara, A., Jacquelien M. A. Scherpena. (2020). Robust Load Frequency Control of Nonlinear Power Networks. International Journal of Control, Vol. 93, No. 2, pp. 346-359.

10. Semenov, A. S., Semenova, M. N., Bebikhov, Yu. V. (2019). Development of Universal Mathematical Model of Electrical Power Supply System of Area of Industrial Enterprise. International Russian Automation Conference (RusAutoCon), 8867704.

11. Panteleev, V., Zilberman, S., Pilyugin, G., Petukhov, R., Sizganova, E., Mashukov, M. (2018). Optimization model of power supply system of industrial enterprise. 9th International Multidisciplinary Scientific and Research Conference on Modern Issues in Science and Technology Workshop in Advanced Technologies in Aerospace, Mechanical and Automation Engineering, MISTAerospace 2018, Vol. 450, No. 7, 072011.

12. Bondarenko, G. A., Budko, D. V. (2015). Mathematical modeling of air supply system of industrial enterprises. Compressor and Power Machine Industry, Vol. 42, No. 4, pp. 29-33.

13. Lipchanskiy, A. Yu., Zhatkin, A. N. (2018). Analysis of Air Power Supply Efficiency in Terms of Compressed Air Consumers in Gaisky Gok Mine. Gornyy Informatsionno-Analiticheskiy Byulleten', № 1, pp. 76-82 [in Russian].

14. Mousavi, A., Siervo, H.R.A. (2017). Automatic Translation of Plant Data into Management Performance Metrics: A Case for Real-Time and Predictive Production Control. International Journal of Production Research, Vol. 55, No. 17, pp. 4862-4877

15. Guo, Y., Guo, L.Z., Billings, S.A., Coca, D., Lang, Z.Q. (2014). A Parametric Frequency Response Method for Non-Linear Time-Varying Systems, International Journal of Systems Science. Vol. 45, No. 10, pp. 2133-2144.

16. Cormen, T. H., Leiserson, Ch. E., Rivest, R. L., Stein, C. (2013). Introduction to Algorithms, Third Edition. Williamspublishing, Moscow. P. 1328 [in Russian].

17. Altendorfer, K. (2019). Effect of Limited Capacity on Optimal Planning Parameters for a Multi-Item Production System with Setup Times and Advance Demand Information. International Journal of Production Research, Vol. 57, No. 6 , pp. 1892-1913.

18. Trebuna, P., Pekarcikova, M., Kliment, M. (2019). Simulation Model Creation for Verifying the Production Capacity of a Production Line and Sizing In-Process Inventory. Acta Mechanica Slovaca, Vol. 23, No. 1, pp. 38-43. 
19. Seow, Y., Rahimifard, S. (2011). A Framework for Modelling Energy Consumption within Manufacturing Systems. CIRP Journal of Manufacturing Science and Technology, Vol. 4, No. 3, pp. 258-264

20. Mukhoid, O.V., Kostornoi, O.S., Shyfrin, D. M. (2018). Selection of the Optimal Software for Designing Expert Systems. Journal of Engineering Sciences, Vol. 5, No. 2, pp. 10-15.

21. Dexiang Wu, Desheng Dash Wu, Roy H. Kwon (2017). Optimizing Data-Driven Network under Limited Resource: A Partial Diversification Approach. International Journal of Production Research, Vol. 57, No. 21, pp. 6875-6892.

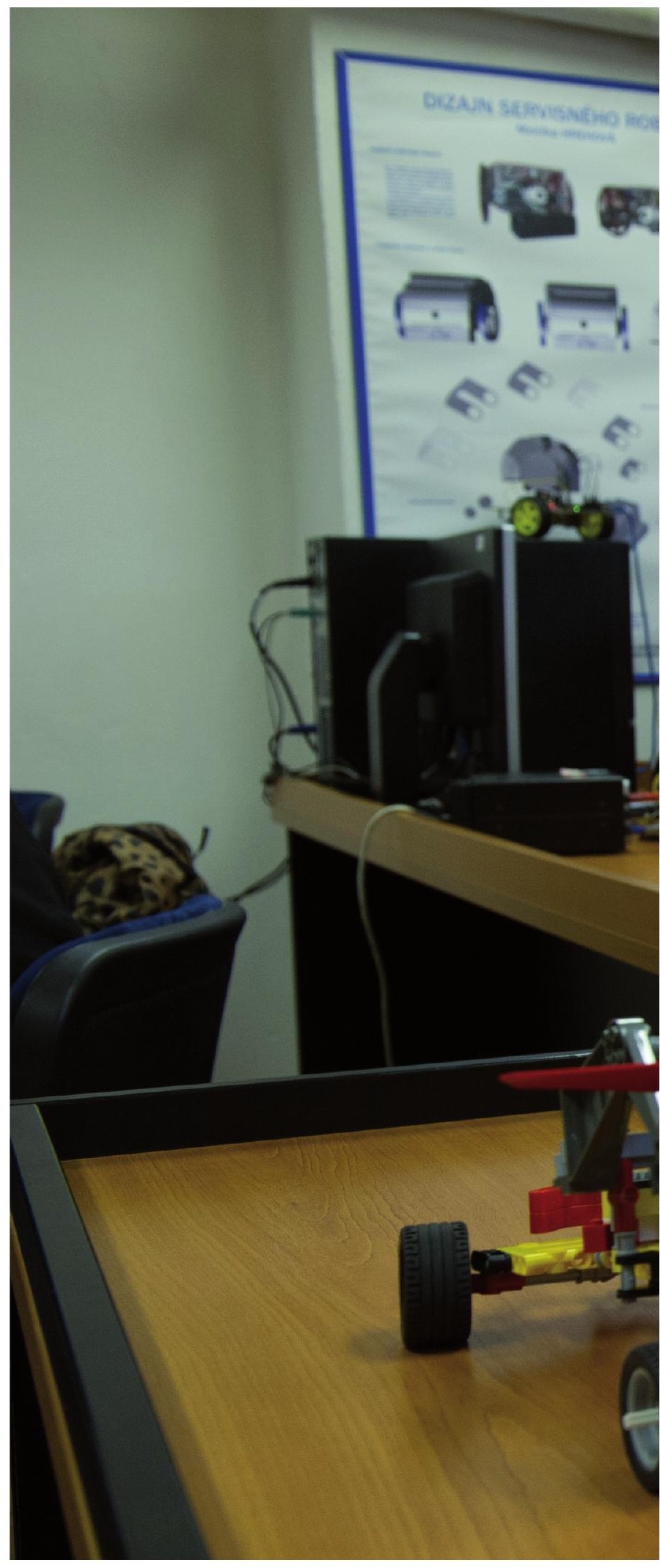

